\title{
Probiotics, Organoleptic and Physicochemical Properties of Vegetable Milk Based Bio-ice cream Supplemented with Skimmed Milk Powder
}

\author{
Mohamed Omer Elsamani ${ }^{1,2}$ \\ ${ }^{1}$ Department of Basic Medical Sciences, University of Al-Baha, Baha City, Kingdom Saudi Arabia \\ ${ }^{2}$ Department of Food Sciences \&Technology, University of Omdurman Islamic, Khartoum, Sudan \\ Emailaddress: \\ mhmdomer6@gmail.com \\ ${ }^{*}$ Correspondingauthor (M. O. Elsamani)
}

\section{Tocitethisarticle:}

Mohamed Omer Elsamani. Probiotics, Organoleptic and Physicochemical Properties of Vegetable Milk Based Bio-ice cream Supplemented with Skimmed Milk Powder. International Journal of Nutrition and Food Sciences. Vol. 5, No. 5, 2016, pp. 361-366. doi: $10.11648 /$ j.ijnfs.20160505.17

Received: August 9, 2016; Accepted: August 18, 2016; Published: October 17, 2016

\begin{abstract}
The aim of the present study was to evaluate non fermented probiotic ice cream made from vegetable (lupine and peanuts) milk, and to evaluate its probiotics, organoleptic and physicochemical characteristics. Ice cream samples were produced from blends of vegetable milk and skimmed milk powder together with the added Probiotics bacteria of Lactobacillusacidophilus and Bifidobacterium. lactis. The changes of Bio-ice cream qualities and survival of added microbes were evaluated at 0,1 , and 30 days. The viable of $L$. acidophilus decreased by 1.62 and $2.05 \log$ cycles in lupine and peanuts milk ice creams throughout 30 days storage respectively. The counts of $B$. lactis reduced by 1.32 and $2.22 \log$ cycles in lupine and peanuts ice creams respectively. Regardless of ice cream color, incorporation of vegetable milk ice cream significantly $(\mathrm{P} \leq 0.05)$ enhanced the taste, texture, flavor, and overall acceptability of ice cream. The highest total solids and protein were found in ice creams containing peanuts milk and lowest fat and total acceptability were found in ice creams containing lupine milk. The produce of ice cream with vegetable milks developed the growth and viability of $B$. lactis and L. acidophilus.
\end{abstract}

Keywords: Bio- ice cream, Lupine, Peanut Milk, Probiotic, Bacteria

\section{Introduction}

Consumer is looking for the functional foods can offer more health benefits. Full-fat milk is rich in saturated fatty acids, which has been shown to significantly elevate total, Low-density lipoprotein (LDL), and high-density lipoprotein (HDL)-cholesterol) [4] and [3] which has long been associated with increased risk of cardiovascular disease. Functional food that contains viable probiotics in particular addresses the improvement in intestinal micro flora activation of the immune system, reduction in serum cholesterol and inhibition of potential pathogens [12]. However, these probiotics must be present in adequate amount $\left(10^{6}-10^{7} \mathrm{cfu} / \mathrm{g}\right)$ at the time of consumption in order to render it being effective [13].Fermented yogurt and milk can effectively be used to deliver probiotic bacteria. The former unfortunately may cause loss of viable probiotic due to $\mathrm{pH}$ reduction and accumulation of organic acids as a result of fermentation [14]. In this regard ice cream, due to its neutral $\mathrm{pH}$, may be used to deliver the probiotics [15]. Partial replacement cow milk with vegetable milks such as soy milk could improve the $\mathrm{pH}$ of probiotic ice cream resulting increased the survival of probiotics [16]. On the other hand, Ice cream is a delicious, wholesome, nutritious frozen dairy product, which is extensively consumed in different parts of the world. Ice cream has nutritional significance but encompasses no therapeutic properties [17]. Ice cream is traditionally made from cow s milk and thus contains about $16 \%(\mathrm{w} / \mathrm{w})$ lactose [18]. The demand for alternatives to cows' milk is growing due to problems 
with its lactose (Lactose intolerance) and cholesterol contents and desire for vegetarian alternatives. Ice cream can be made a functional food by adding fruits, protein rich ingredients and also using vegetable milk such as coconut and soy milks and the addition of probiotics. Moreover, the lupine and peanut milks contain unique nutrient compositions in peanut and lupine milks can support the growth and survival of the lactic acid bacteria in ice cream and thus could improve the health benefits and nutritional components and health benefits of probiotic ice creams.

In particular, lupine proteins are receiving attention in terms of health benefits, particularly in relation to a number of conditions now known as 'metabolic syndrome' which includes a cluster of factors such as, obesity, high blood pressure, insulin resistance and elevated blood cholesterol (5).

Lupine enriched foods have the potential to: beneficially influence satiety (appetite suppression) and energy balance [10], beneficially influence glycaemic control [6], improve blood lipids [7], reduce hypertension [8] and improve bowel health [9]. Partial replacement of cow milk with vegetable milks may affect the physical properties of ice creams. Fortification of yoghurt ice cream with soy protein has been shown to improve the textural quality of the product including firmness and viscosity [19]. Lecithin in the soy also acts as emulsifiers which increase the viscosity and stability of ice cream, refined texture and extend the melting time [20]. Abdullah et al. [21] improved the quality of ice cream by using different ratios of skim milk in soymilk blend and found that large quantity of skim milk in soymilk decline beany flavour of soy beans and increased quality of ice cream. Fatemeh and Other authors [22] Effects of Vegetable Milk on Survival of Probiotics and Rheological and Physicochemical Properties of Bio-ice cream, studied the Physicochemical and Rheological properties of soy and coconut milk ice cream by adding soy oil and sugar contents and found the addition of sugar and replacing skim milk powder with in Vegetable milk ice cream increased ice cream mix viscosity and reduced melting rate of ice cream. The present study was carried out to investigate the effect of lupine and peanut milks on the survival of probiotic in ice cream during storage and the physicochemical and organoleptic properties of non fermented Bio-ice cream. There has been a shortage of milk production. Thus, the supplementation and/or substitution of cow milk with lupine and peanut milk would improve the yield and nutritional quality of ice cream at a comparatively lower cost. Up to now, no work has been published on producing ice cream using cow milk supplemented with Vegetable milk (lupine and peanut milk). Therefore, the aim of the present study was to investigate the effect of incorporation of Vegetable milk on physicochemical, microbiological and organoleptic characteristics of Bio-ice cream.

\section{Materials and Methods}

\subsection{Bacteria Strain}

Lactobacillus acidophilus and Bifidobacteriumbifidum were obtained as pure freeze-dried probiotic culture from CHR-Hansen (Horsholm, Denmark).

\subsection{Preparation of Starter Cultures}

Each one gram of strain was cultured in $100 \mathrm{~mL}$ of sterilized skimmed milk $(10 \mathrm{w} / \mathrm{v})$, simplified by the addition of $0.05 \%(\mathrm{w} / \mathrm{v}) \mathrm{L}-\mathrm{Cys}-\mathrm{HCl}, 1 \%(\mathrm{w} / \mathrm{v})$ yeast extract and $2 \%(\mathrm{w} / \mathrm{v})$ glucose. The incubation was carried out under aerobic condition in a water bath $\left(40^{\circ} \mathrm{C}\right)$ until $\mathrm{pH}$ was reached to 5.0 [23].

\subsection{Preparation of Vegetable Milk}

Lupine and peanuts milk were extracted from the seeds by the methods according to [1:2].

\subsection{Ice Cream Production}

Fresh pasteurized and homogenized milks (lupine and peanuts milk), skimmed milk powder, butter, sugar, and vanilla was purchased from local super market. Stabilizer (Danisco AS, Copenhagen, Denmark) containing cellulose gum, guar gum, mono- and diacyl- glycerol's of fatty acid, was used as stabilizer. Ice cream mix formulated according to some properties of mixture milks (Table 1) such that it had $38.7 \%-40.8 \%$ total solids and $10-10.5 \%$ fat for a total batch of $100 \mathrm{~kg}$ (Table 5).

The vegetable milk (lupine and peanuts milk) was initially heated to $50^{\circ} \mathrm{C}$ followed by the other additives. The mixture was mixed at $65^{\circ} \mathrm{C}$ in two stages by a homogenizer with $16000 \mathrm{rpm}$ for $5 \mathrm{~min}$ followed by pasteurization (10 $\mathrm{min}$ heating at $80^{\circ} \mathrm{C}$ followed by cooling to $4^{\circ} \mathrm{C}$ ). The mixture was aged overnight at $4{ }^{\circ} \mathrm{C}$ prior to the addition of each probiotic culture $(4 \% \mathrm{w} / \mathrm{w})$ followed by immediate freezing in batch ice cream maker (1.5 L, Baumatic Gelato1SS). The frozen mixture was packed in $100 \mathrm{~mL}$ plastic cups and then stored in a freezer $\left(-18^{\circ} \mathrm{C}\right)$. Three different batches of ice cream per treatment were manufactured.

\subsection{Physicochemical Analysis}

The vegetable Milk and ice creams were analyzed for $\mathrm{pH}$ by a digital $\mathrm{pH}$ meter and for titratable acid (TA) by titrating a sample (10g) with $\mathrm{NaOH} \quad(0.1 \mathrm{~N})$ using phenolphthalein $(0.1 \mathrm{w} / \mathrm{v})$ as an indicator. The dry matters were measured by drying samples at $100 \pm 1^{\circ} \mathrm{C}$ for $3.5 \mathrm{~h}$ using an air oven [24]. The protein and fat contents of milk and ice creams were measured by the Kjeldahl and Soxhlet methods respectively [24]. All chemical analyses were carried out in triplicate. 
Table 1. Physicochemical compositions of lupine and peanuts milk

\begin{tabular}{lllllll}
\hline Parameters & $\mathbf{p H}$ & T.S(g/100g & T.A(\%lactic acid) & M.C(g/100g) & Protein(g/100g) & Fat(g/100g) \\
\hline Peanuts Milk & $7.03 \pm 0.10$ & $14.67 \pm 0.10$ & $0.10 \pm 0.10$ & $85.33 \pm 0.12$ & $5.40 \pm 0.12$ & $5.00 \pm 0.12$ \\
Lupine Milk & $6.30 \pm 0.10$ & $12.14 \pm 0.07$ & $0.60 \pm 0.01$ & $87.86 \pm 0.12$ & $5.10 \pm 0.12$ & $3.30 \pm 0.12$ \\
\hline
\end{tabular}

Values are means of triplicate samples $( \pm \mathrm{SD})$.

T.S: Total solids

T.A: Titritable acidity

M.C: Moisture content

Table 2. The content of components used in Bio-ice cream made from vegetable milk (\%by weight).

\begin{tabular}{llllllll}
\hline Ice cream mixture & Milk & Skimmed Milk Powder & Sugar & butter & water & Stabilizer & Vanillin \\
\hline Lupine & 50.0 & 10.0 & 15.0 & 4.4 & 20.0 & 0.5 & 0.1 \\
Peanuts & 50.0 & 10.0 & 15.0 & 4.4 & 20.0 & 0.5 & 0.1 \\
\hline
\end{tabular}

\subsection{Bacteriological Analysis}

The viability of probiotics was measured immediately after inoculating the probiotic cultures and after 1 and 30 days of frozen storage at $-20^{\circ} \mathrm{C}$. The samples $(10 \mathrm{~g})$ were decimally diluted with sterile peptone water $(1 \mathrm{~g} \mathrm{~L}-1$; Merck). One mL aliquot dilutions were pour plated in triplicate on MRS agar for L. acidophilus and MRS agar supplemented with $0.05 \%$ (w/v) L-Cys-HCI (Merck) for $\underline{B}$. lactis. The plates were incubated at $38 \pm 1^{\circ} \mathrm{C}$ for $72 \mathrm{~h}$ under aerobic condition with $5 \% \mathrm{CO}_{2}$ (v/v) for L. acidophilus and anaerobic condition (Anaerocult A) for B. lactis. The bacterial viability was represented as survival rate [23].

Table 3. Probiotic bacteria count of Bio- ice creams with different milks.

\begin{tabular}{lllll}
\hline Bio-ice creams & Mixture(0days)(Log10cfu/g) & Icecream1days(Log10cfu/g) & Icecream30days(Log10cfu/g) & Survival Rate (\%) \\
\hline L.L & $8.87 \pm 0.12$ & $8.85 \pm 0.15$ & $7.25 \pm 0.15$ & $97.57 \pm 0.15$ \\
L.B & $8.59 \pm 0.12$ & $8.57 \pm 0.15$ & $7.27 \pm 0.15$ & $98.85 \pm 0.15$ \\
P.L & $9.58 \pm 0.12$ & $9.46 \pm 0.15$ & $7.53 \pm 0.15$ & $98.87 \pm 0.15$ \\
P.B & $9.87 \pm 0.12$ & $9.74 \pm 0.15$ & $7.65 \pm 0.15$ & $97.85 \pm 0.15$ \\
\hline
\end{tabular}

Values are means of triplicate samples $( \pm \mathrm{SD})$.

L.L: ice creams inoculated with Lactobacullusacidophilus made using lupine milk or P.L: peanut milk

LB: ice creams inoculated with Bifidobacteriumbifidum made using lupine milk or P.B: peanut milk

\subsection{Organoleptical Analysis}

The organoleptically characteristics of the ice creams were evaluated following the IDF standards [11]. A trained panel of 12 members, composed of adult male (4,age ranged from 25 to 35) and female (8,age ranged from 25 to 40), was assigned to determine the quality of the ice creams (color, flavor, taste, texture and overall acceptability). Members were asked to score $1-5$ hedonic scale $(1=$ poor, 2 = acceptable, $3=$ good, $4=$ very good and $5=$ excellent). The samples were randomized and presented using tag for each one. To determine the differences in judges 'response, the means cores were analyzed by Duncan's multiple range tests.

Table 4. Organoleptic property scores of ice creams with different milks.

\begin{tabular}{llllll}
\hline Bio-ice creams & Color & Texture & Taste & flavor & Overall acceptability \\
\hline L.L & $3.22 \pm 0.03^{\mathrm{a}}$ & $3.18 \pm 0.03^{\mathrm{a}}$ & $3.36 \pm 0.03^{\mathrm{b}}$ & $3.38 \pm 0.05^{\mathrm{a}}$ & $3.32 \pm 0.01^{\mathrm{a}}$ \\
L.B & $3.32 \pm 0.05^{\mathrm{a}}$ & $3.12 \pm 0.02^{\mathrm{b}}$ & $3.32 \pm 0.03^{\mathrm{b}}$ & $3.32 \pm 0.05^{\mathrm{b}}$ & $3.30 \pm 0.05^{\mathrm{a}}$ \\
P.L & $3.22 \pm 0.05^{\mathrm{a}}$ & $3.33 \pm 0.05^{\mathrm{b}}$ & $3.45 \pm 0.03^{\mathrm{a}}$ & $3.23 \pm 0.05^{\mathrm{c}}$ & $3.35 \pm 0.05^{\mathrm{a}}$ \\
P.B & $3.23 \pm 0.03^{\mathrm{a}}$ & $3.32 \pm 0.03^{\mathrm{b}}$ & $3.37 \pm 0.05^{\mathrm{b}}$ & $3.22 \pm 0.05^{\mathrm{c}}$ & $3.33 \pm 0.05^{\mathrm{a}}$ \\
\hline
\end{tabular}

Values with different letters in the same column are significantly $(P<0.05)$ different

L.L: Ice creams inoculated with L.acidophilus made using lupine milk

P.L: Ice creams inoculated with Lacidophilus made using peanut milk

LB: ice creams inoculated with Bifidobacteriumbifidum made using lupine milk

P.B: ice creams inoculated with Bifidobacteriumbifidum made using peanut milk 
Table 5. The physicochemical compositions of vegetable milk and probiotic ice creams, made using lupine and peanut milks.

\begin{tabular}{llllll}
\hline $\begin{array}{l}\text { Vegetable milk/ } \\
\text { Bio-ice creams }\end{array}$ & T.S(g/100g) & pH & T.A(\%lactic acid) & Protein(g/100g) & Fat(g/100g) \\
\hline L.M & $12.0 \pm 0.1$ & $7.00 \pm 0.5$ & $0.72 \pm 0.2$ & $4.40 \pm 0.5$ & $3.30 \pm 0.1$ \\
P.M & $14.67 \pm 0.1$ & $7.03 \pm 0.3$ & $0.91 \pm 0.1$ & $5.20 \pm 0.5$ & $5.00 \pm 0.3$ \\
L.L & $39.0 \pm 0.3$ & $7.11 \pm 0.1$ & $0.72 \pm 0.4$ & $2.13 \pm 0.1$ & $10.0 \pm 0.2$ \\
L.B & $38.7 \pm 0.1$ & $7.15 \pm 0.1$ & $0.70 \pm 0.3$ & $2.21 \pm 0.3$ & $10.3 \pm 0.1$ \\
P.L & $39.9 \pm 0.2$ & $6.71 \pm 0.1$ & $0.12 \pm 0.1$ & $2.8 \pm \pm 0.1$ & $10.3 \pm 0.1$ \\
P.B & $40.8 \pm 0.1$ & $6.74 \pm 0.1$ & $0.11 \pm 0.1$ & $2.32 \pm 0.1$ & $10.5 \pm 0.2$ \\
\hline
\end{tabular}

Values are means of triplicate samples $( \pm \mathrm{SD})$.

L.M: lupine Milk

P.M: Peanut Milk

L.L: Ice creams inoculated with L.acidophilus made using lupine milk

P.L: Ice creams inoculated with L.acidophilus made using peanut milk

LB: ice creams inoculated with Bifidobacteriumbifidum made using lupine milk

P.B: ice creams inoculated with Bifidobacteriumbifidum made using peanut milk

\subsection{Statistical Analysis}

The viability of the probiotic micro-organisms were evaluated at three times of storage $(0,1$ and 30 days), in triplicates and the results were expressed as mean \pm S.E.M (standard mean error) values. The statistical analysis was performed using Minitab programmer (1998). Three separate samples were analyzed and mean values were calculated. The data were assessed by analysis of variance (ANOVA) and followed by Duncan's multiple range method for mean comparison. The mean values and the standard error were calculated from the data obtained with triplicate trials. The criterion for statistical significance was $(\mathrm{P}<0.05)[25]$.

\section{Results and Discussion}

\subsection{Viability of Probiotic Bactrian Ice Cream}

Table3: shows the changes in bacterial counts in nonfermented ice creams made using vegetable milks. The survival rate of probiotic bacteria in ice creams after 30 days tend to be higher in B.bifidum (7.65 and $7.27 \operatorname{logcfug}^{-1}$ for peanut and lupine milk ice cream respectively) than in the presence of Lactobacullus acidophilus (7.53 and 7.25 $\operatorname{logcfug}^{-1}$ peanut and lupine milk ice cream respectively) (Table3). These finding agreed with Fatemeh et al. [27] they found the survival rate of probiotic bacteria in ice creams after 30 days tend to be higher in B. bifidum (7.767 and 7.371 $\log$ cfug ${ }^{1}$ for soy and coconut ice cream respectively) than in L. acidophilus (7.847 and $6.870 \mathrm{log}$ cfug_ ${ }^{1}$ for soy and coconut ice cream respectively).However, the decline in viable bacterial counts due to freezing is associated with freeze injury on these cells. In addition the mechanical stresses associated with the mixing and freezing process which incorporates oxygen in to the mixture may be responsible in further reduction in bacterial count [23]. The survival of both probiotics in ice cream was high $(\mathrm{P}<0.01)$ in the presence of lupine and peanuts milk. This could be explained by the high $\mathrm{pH}$ of lupine and peanuts ice creams which are known to be conducive to probiotic survival since these organisms are susceptible to inactivation when stored in acidic conditions [28]. As a result probably, these proteins can cover probiotics as a capsule. The high survival rate of $L$. Acidophilus cells during the frozen storage in other studies was attributed to the protection provided to the cells by the solid ingredients and the high fat content of the ice cream in the form of emulsion [29].

Heenan et al.,[16] demonstrated that the survival of probiotics increased in the frozen soy dessert due to the prevailing neutral $\mathrm{pH}$. The highest survival of both probiotics was in lupine milk ice cream. It is probably due to the lupine milk proteins which provide physical protection against freezing damage by encapsulating probiotics by form stable net work looks like a gel structure [26].

\subsection{Organoleptic Property}

Table 4: shows the organoleptic property scores in non fermented ice creams made using vegetable milks (Table4). The presence of either L. Acidophilus or B.bifidum had no significant influence on the Color and Overall acceptability properties of both probiotics ice creams. The highest $(\mathrm{P} \leq 0.05)$ scores of overall acceptability was (3.35) seen in peanut milk ice cream than the lowest core (3.30) seen in lupine milk ice cream. It is probably due to the lupine milk beany flavors, which could be explained by the soy milk woody or beany off flavors [21].

\subsection{Physicochemical Parameters of Milks and Probiotic Ice Creams Made Using Lupine and Peanut Milk}

Table5: The physicochemical compositions of the probiotic ice creams, lupine and peanut milks are shown in Table5. The highest (7.15) $\mathrm{pH}$ value and lowest $(0.70 \%)$ titritable acidity (TA) and fat content (10\%) were in ice creams containing lupine milk. The protein contents varied between $2.51 \%$ to $2.32 \%$ in ice creams inoculated with B.bifidum made using lupine and peanut milk, respectively. The highest $(40.8 \%)$ total solids, fat $(10.5 \%)$ and protein $(40.8 \%)$ were found in ice creams containing peanuts milk and lowest (10.0\%) fat content and total acceptability (3.30) 
score were found in ice creams containing lupine milk. The total solids content of $40.8 \mathrm{~g} / 100 \mathrm{~g}$ obtained for sample containing peanut milk is higher $(\mathrm{P} \leq 0.05)$ than other samples $(39.0 \mathrm{~g} / 100 \mathrm{~g}$ and $38.8 \mathrm{~g} / 100 \mathrm{~g})$ for sample containing lupine milk. This may be due the higher content of protein and fat of peanut milk. Lupine milk based ice creams showed lower $(\mathrm{P} \leq 0.05)$ fat content than ice cream made with peanut milk. This may be due to that lupine milk has generally low fat $(3.30 \mathrm{~g} / 100 \mathrm{~g})$ content compared to that of peanuts milk $(5.0 \mathrm{~g} / 100 \mathrm{~g})$.

\section{Conclusions}

Probiotic Food is being one of the largest markets of functional foods represent a vast growth potential for the food industry and may be explored through the development of innovative ingredients, processes, and products. This research proves that the rear serious confirmations those supporting develop of new lupine and peanut ice cream formulation and application of growing probiotic culture have important role in design of various functional products including vegetable milk ice cream. Stability during storage is important characteristics that are proved observing Probiotic characteristics of produced samples of vegetable milk ice cream. Moreover, incorporation of lupine and peanuts milk in ice cream manufacturing resulted in cost saving and improvement of the nutritional value and organoleptic quality.

\section{References}

[1] Elsamani, M. O., Habbani, S.S., Babiker, E.E., and Mohamed, A.I.A (2014) Biochemical, microbial and sensory evaluation of white soft cheese made from cow and lupine milk. Journal LWT-Food Science and Technology vol 59(1):553-559.

[2] Elsamani, M. O. and Mohamed Ahmed I. A. (2014) Physicochemical Characteristics and Organoleptic Properties of Peanuts Milk-Based Yoghurt Fortified With Skimmed Milk Powder. Journal of Research in Applied sciences, Vol., 1(4):68-72.

[3] Wood, R ., Kubena, K., O'Brien, B., Tseng,S. and Martin, G.(1993) Effect of butter, mono-and poly unsaturated fatty acid enriched butter, trans fatty acid margarine, and zero trans fatty acid margarine on serum lipids and lipoproteins in healthy men.JournalofLipidResearch,34,1-11.

[4] Lee,Y.P.,Mori,T.,Sipsas,S.,Barden,A.,Puddey,I.,Burke,V.,etal.( 2006).Lupine richer bread increases satiety and reduces energy intake acutely. American, Journal of Clinical Nutrition, $84,975-980$.

[5] Arnoldi, A.(2005).Optimized processes for preparing healthy and added value food in gradients from lupine kernels, the European protein-rich seeds legume. In Preceding soft he Final Conference of the European Project. Milan, November 9-10, 2005. Aracne (202pp.).

[6] Hall, R. S., Thomas, S.J., \& Johnson, S.K. (2005).Australian sweet lupine flour addition reduced the glycaemic index of a white bread breakfast without affecting palatability in healthy human volunteers. Asia Pacific, Journal of Clinical Nutrition, 14,91-97.

[7] Martins, J. M., Riottot, M., deAbreu, M. C., Viegas Crespo, A.M., Lança, M.J., Almeida, J.A., et al.(2005). Cholesterollowering effects of dietary blue lupine (Lupinus angustifolius L.) in intact and ileorectal anastomosed pigs. Journal of Lipid Research, 46, 1539 -1547.

[8] Pilvi,T.K.,Jauhiainen,T.,Cheng,Z.J.,Mervaala,E.M.,Vapaatalo, H.,\&Korpela,R.(2006). Lupine protein attenuates the development of hypertension and normalizes the vascular function of NaCl-loaded Goto Kakizakirats. Journal of Physiological Pharmacology, 57,167-176.

[9] Johnson, S. K., Chua, V., Hall, R.S., \& Baxter, A.L. (2006).Lupine kernel fibre foods improve bowel function and beneficially modify some putative faecal risk factors for colon cancer in men. British Journal of Nutrition, 95,372-378.

[10] Kris Etherton, P.M., Derr, J. and Mitchell, D.C. (1993). The role of fatty acid saturation on plasma lipids, lipoproteins, and a polipoproteins. Effects of whole food diets high in cocoa butter, olive oil, soy bean oil, dairy butter, and milk chocolate on the plasma lipids in young men. Metabolism, 42,121-129.

[11] FIL-IDF99B. (1995). Sensory evaluation of dairy products. Brussels: FIL-IDF.

[12] Grajek ,W., A. Olejnik ,and A. Sip, "Probiotics, prebiotics and antioxidants as functional foods, "ActaBiochim PolonicaEnglishedition-.,vol.52,no.3,pp.665-671,July.2005.

[13] Siró, I., Challenges of Beneficial Health Claims. In M.T. Liong (Eds.), Probiotics. Springer, BerlinHeidelberg.2011, pp.243268.

[14] Donkor, O N., Henriksson, A., Vasiljevic, T and N. Shah, "Effect of acidification on the activity of probiotics in yoghurt during cold storage,"International Dairy Journal. vol.16, no.10, pp.1181-1189, Feb.2006.

[15] Akın, M., M. Akın, and Z. Kırmac1, "Effects of insulin and sugar levels on the viability of yogurt and probiotic bacteria and the physical and sensory characteristics in probiotic ice cream, "Food chemistry,vol.104,no.1,pp.93-99.Feb.2007.

[16] Heenan, C., et al., "Survival and sensory acceptability of probiotic microorganisms in a non fermented frozen vegetarian dessert," LWT-Food Science and Technology., vol.37, no.4, pp.461-466.Jan.2004.

[17] Salem, M. M., F.A. Fathi, and R. Awad, "Production of probiotic ice cream, "Polish journal of food and nutrition sciences., vol.14/55,no.3,pp.267-271.2005.

[18] Supavititpatana, P. and T. Kongbangkerd,“ The effect of partial replacement of non-fat dry milk with sodium caseinate on qualities of yogurt ice cream from coconut milk , "International Food Research Journal.vol.18.pp.439443.2011 .

[19] Mahdian, E., M. Mazaheri Tehrani ,and M. Nobahari, "Optimizing Yoghurt-Ice Cream Mix Blend in Soy Based Frozen Yoghurt," Journal of Agricultural Science and Technology, vol.14,no.6, pp.1275-1284.2012.

[20] Samoto,M.,Maebuchi,M.,Miyazaki,C.,Kugitani,H.,Kohno,M., Hirotsuka,MandMKito,"Abundant proteins associated with lecithin in soy protein isolate, "Food chemistry., vol.102.no.1,pp.317-322.Aug.2007 
[21] Abdullah, M. , Saleem -ur-Rehman., Zubair, H., Saeed, H.M., Kousar, S and M Shahid, "Effect of skim milk in soy milk blend on the quality of ice cream, "Pakistan Journal of Nutrition, vol.2,no.5,pp .305-311.Jan 2003.

[22] Kerdchouay P, Surapat S, "Effect of Skimmed Milk Substitution by Whey Protein Concentrate in Low-fat Coconut Milk Ice Cream, "In: The $46^{\text {th }}$ Kasetsart University Annual Conference.Jan29-Feb1,Bangkok,Thailand,2008,pp.262-269.

[23] Magarinos, H., Selaive ,S., Costa, M., Flores, M and O, Pizarro, "Viability of probiotic microorganisms (Lactobacillus acidophilus $\mathrm{La} 5$ and Bifidobacterium animal is subsp. lactisBb12) in ice cream .International Journal of Dairy Technology, vol.60,no.2,pp.128-134.Apr.2007.

[24] AOAC. Official Methods of Analysis of AOAC International. 18 the dn. Association of Official Analytical Communities International, Maryland, USA. 2005.

[25] Homayouni, A. ,et al., Effect of microencapsulation and resistant starch on the probiotic survival and sensory properties of symbiotic ice cream. Food chemistry. vol.111, no.1, pp.50-55, Mar.2008.
[26] Akesowan, A, "Influence of soy protein isolate on physical and sensory properties of ice cream," Thai J Agric Sci.,vol.42, no.1, pp.1-6.2009.

[27] Fatemeh. Aboulfazli, Ahmad salhin, Baba, and Misni, Misran (2014). Effects of Vegetable Milk on Survival of Probiotics and Rheological and Physicochemical Properties of Bio-ice cream. International Conference on Biological and Medical Sciences (ICBMS'2014) Jan.15-16.

[28] Hagen, M. and J.A.Narvhus, "Production of ice cream containing probiotic bacteria,"Milchwissenschaftvol.54, pp. 265-268.1999.

[29] Godward, G. and K. Kailas apathy, "Viability and survival of free, encapsulated and co-encapsulated probiotic bacteria in ice cream, Milchwissenschaft"vol.58, No.3-4, pp.161163.2003 